\title{
Reconstructing the Global Education and Learning Strategies to Enhance 21st Century Learning Skills: Learning Experience on a Global Perspective Across Curriculum
}

\author{
Dr. Teck Choon,TEO \\ Associate Dean, RVi Institute \\ Postdoctoral Researcher \\ Mandalay, Myanmar
}

\author{
Prof. Dr. Kim Cheng Patrick, LOW \\ Chartered Marketer, Certified MBTI Administrator, \\ \& Certified Behavioural Consultant/Visiting Professor, University of South Pacific. \\ Professor, Dean, Construction Technologies and Management \& Director, Scientific Center, Kazakh American \\ University (KAU) \& Kazakh Leading Academy of Architecture \& Civil Engineering (KazGASA) (end May 2017 \\ to early Jan 2018) \\ Associate Researcher, APIAR
}

\begin{abstract}
This study examines a private educational institution (PEI) in Singapore on its global education and learning strategies, with the intent of uncovering strategies on new learning experience of students globally. As Suto and Eccles (2014) noted that the inter-disciplinary skills most commonly regarded as essential for the 21st Century are problem-solving, ICT operations and concepts, communication, collaboration, and information literacy. Given the technological advances, the teaching and learning strategies have been linked to learning experiences. For example, the hub and spoke TNE (Trans-National Education) model is increasingly critical that the programmes offered between the destinations are aligned as well. To meet some of the learning outcomes and to create a collaborative value chain, there must be more interaction between the destination campuses. Programmes schedules and project must now be aligned; student projects can now be cross-destination with students interacting with one another through skype and learning experience conference calls to meet to discuss projects for a collaborative project presentation, led by teachers on both sides. Interaction between teachers in different destinations becomes a key component for success in classrooms and student experience. Conversely, the ability of school to assess student 21st century skills via ICT and LMS will become acutely relevant and appropriate in the teaching and learning communities.
\end{abstract}

Keywords: 21 st century skills, learning experience, leadership, workplace, global education, technology, digital disruption, transnational education

\section{Introduction}

The compelling need for knowledge and technical skills to succeed in today's rapidly changing world is perhaps very different to those upon which previous 20th Century education systems have traditionally focused. For many years, we have heard that today's students are not really ready for college, work and life. To address this, rhetorically we assign the blame against the school system, the managers and the educators that run them. Educators both in public and private sectors over the years have attempted to satisfy these demands by instituting many different types of reform programmes. Most of these reform programmes, while they may have been well intentioned, tend to be either overly simplistic in nature or unsuitable. Very often these programmes have not taken into account the complexity of the diverse cultures and economic differences that exist in Singapore. The outcome of these reform programmes has often created inadvertent consequences vis systemic cheating by teachers and administrators or implementation resistance (Schmoker, 1999; Greenberg \& Barron, 2000; Cuban, 2011). For example, in the case of education in Singapore, a controversial topic that has often been in the limelight is whether the over-emphasis of academic success in our meritocratic society has allowed maximum educational opportunities for students of all abilities. It is important to note that everyone has a right to learn and none of us possess the same level of ability when it comes to learning. 
As Singapore moves towards a more inclusive society, greater attention has turned to special education and emphasis has been given to equipping special education (SPED) students with the knowledge, skills and attributes to become independent and contributing citizens in the 21st century through the revised SPED curriculum framework in 2012. Which articulates a set of desired living, learning and working outcomes (Social-Emotional, Academic, Daily Living, Vocational, the Arts, Physical Education and Sports) in a holistic way (MOE, 2016)?

\section{Continuing Challenges}

In their book, Turning Learning Right Side Up: Putting Education Back on Track, authors Ackoff and Greenberg (2008) point out that today's education system is seriously flawed - it focuses on teaching rather than learning.Today, there are two views that use the word education with differing connotations: one view consists of the schools and colleges of our education system, vis calibration of academic quality prevails. In that view, the output strives to turn out identical replicas of a product called "people educated for the twenty-first century" (Ackoff and Greenberg 2008); the second is the world of information, knowledge, and wisdom, visin which the real population of the world resides when not confined in education systems. In that view, learning occurs naturally, and teaching involves communicating one's wisdom, among other things, to voluntary listeners.

Private Educational Institutions (PEIs) in Singapore have become increasingly diverse too, in the past decade as more and more classrooms are populated with international students from a greater diversity of cultures and languages. PEIs also cater to another group of learners vis local working adult learners, where for reasons missed their university education in their earlier years.

Given the challenges in education, and that since,education in the 21st Century has become global, multi-cultural and inter-connected, acquiring new skills (both hard and soft skills) are imperative to succeed in education and in the workplace. The question of how the development of such skills in learners can best be supported is considered in depth. The learning and teaching strategies include: continuing with modern methods of effective teaching; developing programmes and analytical abilities that cover 21 st Century overtly vis adopting a skills-centred pedagogy in learning institutions; and fostering learning of soft-skills through extra-curricular activities, through independent research work, and internship or industry work-placement. In fact, the 21 st century framework cited possessing core literacy skills is just one of the four core competencies expected of learners to acquire in the work place (Ledward and Hirata 2011). Learners are expected to acquire / research and analyse data, and gain skills such as entrepreneurship, creativity, and innovation skills. Workplace ready graduates with critical thinking skills, competency in communication, ability to work collaboratively and utilising information, media and technology skills are the 21st century competencies (Partnership for 21st century, 2011). The findings of several empirical researches (Felder \& Brent, 2007; Lea et. al., 2003; Shimazoe \& Aldrich, 2010) suggested that collaborative learning has become an essential learning tool to engage students. In keeping abreast with challenging time, the PEIs are slanting towards integrated curriculum which is an ideal method for educating 21 stcentury learners vis teaching students how to communicate, collaborate, and work effectively. According to Cheng (2003), engaging in self-discovery and learning has become the basis of education.

Here, it is worthy to note that in the authors' interaction with their students, some students perceived good data collection is good analysis. "We can analyse well because we are good in mining and gathering data from the internet." It only reflects technical know-how but not academic or analytical savvy. This is not correct since data collection is just dealing with the mass of data or information. The breakdown and organization of data is still necessary to analyse well and forms part of good researching skills. So analysis and awareness of this must be taught and practiced but essentially linked to the workplace thinking, analysis and abilities.

Integrated curriculum includes three main foci: Learning and Innovation Skills, Information, Media and Technology Skills, and Life and Career Skills (Greenhill2010). These are most suitable to the provision of a foundation for the features typically associated with 21 stcentury learning, most notably integrating technology into student centered learning and enhancing subject specific and cross curricular competencies. Teo and Low (2018, p. 76) noted that 'We need to remember that 'what got you here won't keep you here!' Things change, the world changes fast enough to invalidate much of what your company is doing today. So where do you want to go from here?" Indeed so, "a strategy is, basically, what are you going to do to get there, that is, where you want to go. It is a plan for interacting with the competitive environment to attain the company's goals" (Teo and Low, 2018, p. 76). 


\section{Are We Preparing Future Educators Adequately to Succeed this Critical Battle?}

The forces that will shape the world in which we will live, work and provide education are forces such as technological innovation, globalization, mass communication, mass culture and rising consumer expectations is inevitable according to Sturgess (2006).

The issue is not how they might be avoided, but what we must do to adapt. Given the possibility, if some or all combination of these forces converge in ways that create a future radically different from our past experiences and current realities, what then will be the effect of these forces have on schools and their leadership?

To be equitable, many PEIs are successfully engaged in strategies such as:

- Providing high-quality alternative routes to learning and teaching

- Building on private and public partnerships that share common sets of ideas in advancing education standards

- Effectively partnering with centralised institutions to equip teachers to teach effectively with large numbers of culturally and linguistically diverse learners

- Collaboration with external university partners and institutions, providing courses of study in higher education, vocational education and further education

- Effectively providing the Education and Career Guidance for students

- Creating a robust industry experience for students, including internships and industry work placements, and

- Growing anAlumni Network and Continuing Professional Development courses

The extant literature reiterates that where students learn affects the quality of how they learn. To nurture 21st Century Skills, it is then critical that education take shape within flexible, adaptive contexts that inspire a sense of community and promote formal and informal learning. The environment should also allow equitable access to quality learning tools, technologies, and resources (Stover 2018; Black 2007). In order to meet the challenges and demands of the education, collective leadership in PEIs is leading improvement efforts that:

- Provide evidence that the teaching staff in PEIs will have a positive effect on their students' learning

- Go beyond providing content knowledge and prepare teachers to differentiate their instruction to reach all learners, especially those at-risk students and English language learners

- Ensure that teachers receive guidance with mentoring support that requires performance evaluation tied to the teacher tenure and high standards for pedagogy and andragogy practice

\section{What is a Global or Transnational Education?}

To put in context of Singapore PEI, the notion of global education is not something new but can be traced over the course of 20th Century. As the world is becoming increasingly interconnected as a result of massively increased trade and cultural exchange, the relentless pursuit of globalisation, it is small wonder that PEIs seize the opportunity to engage with those (students) who seek an international education but want to stay local for economic or social reasons. The term Global Education (GE) can sometimes be used interchangeably with Transnational Education (TNE) where education is delivered in a country other than the country in which the awarding institution is based. As it stands, it is a collaborative approach of PEIs that bring about how education or academic programmes are offered and delivered to learners, which can bring about a desirable learning experience for learners. It encapsulates a relatively un-tapped segment of learners which is growing. These learners have global aspirations and find more education opportunities and employment mobility regionally or globally. This presents a unique opportunity for PEIs understanding domestic learners and strategically engaging them through via global or transnational education. According to Young (2014) those (students) with global competence:

- Explore their own culture, make comparisons with other cultures and investigate global issues and challenges.

- Think critically and problem solve on issues that demand perspective taking and research skills.

- Develop awareness of cultural diversity and global issues.

The authors acknowledge and give credence that the real-world is increasingly international, interdependent, and diverse world rewards people with global competencies and understanding, such as the ability to make local-toglobal connections, recognise divergent perspectives, think critically and creatively about global challenges and collaborate respectfully in heterogeneous forums (P21, 2014). The challenge is to go beyond present norms and paradigms and reconstruct the global education and implement suitable and effective learning strategies, enhancing 21st Century learning skills. Indeed, the learning experience of students on a global perspective and across curriculum? 


\section{ABC Academy}

Using an example of a private educational institution, $\mathrm{ABC}$ Academy as a platform to understand what it takes to be a global education provider and inculcate 21 st century learning strategies and preparedness for learners.

For PEIs to be global education providers and to achieve return on investments (ROI) and impart 21st century learning skills to students - you will require collective leadership in the PEI-recalibrating current strategies and harnessing digital solutions in delivering curriculum transnationally.

However, turning to strategic leadership in PEIs, it remains the topmost role of the principal while pedagogical leadership is the responsibility of the teachers (Crowther et al., 2000, 2002; Smylie-Hart, 1999). Their relationships have been described by Crowther et al. (2000) as "parallel leadership". Teacher leaders and administrator leaders work in parallel and develop new roles and relationship within the school.

The strategic vision spells out the outcome very clearly. The quality of teaching at this institution should see a paradigm shift. And this shift is indeed determined by the changes in the education sector largely contributed and shaped by the changing learning patterns of students of today. The education industry is certainly a competitive industry with many key players in Singapore; and these include Kaplan Singapore, PSB Academy, Management Development Institute of Singapore, SIM Global Education.

ABC Academy needs to introduce a new education blueprint that would cement the way forward for the next three (3)to five (5) years to address the learning experience on a global perspective across curriculum. It is to be envisaged that the academic department to lead the concepts and put them in practice to ensure this global education vision is met.

The Academy's Education Blueprint can be described as follows:

- Technical competency - to master the subject in depth

- Workplace connectedness and linkage - to understand how the concepts are applied at workplace. The Academy cannot function devoid of the business setting and environment.

- Soft skills development - to learn the skills in presentation, task management, negotiation, public speaking and confidence building and other skills that affect the performance at workplace

- Personal and Character development - to create and/ or develop the correct work attitude and character that allows one to excel

- Simulation and realistic presentations - to put what they learn in a realistic simulated environment to cement the outcome

- Professional and Ethics-driven - to haveand/ or grow the professional and ethical mind-set for doing the right thing as part of an organisation

For the blueprint to be effective, the classroom delivery has to change as well. The move from $1 \mathrm{G}$ (needs to clearly spelt out $1 \mathrm{G}$ ) education, a traditional model where one teaches and the mass listens in front of a chalkboard or white board, continues till today in many educational institutions; to what the authors would label as the $4 \mathrm{G}$ education concept and even beyond that is particularly tailored to today's learners.

Ironically, many educational institutions are still in the $1 \mathrm{G}$ model or slight variations of it, believing they have moved, but actually with very little change. Having the technology in the classroom with without conceptual change in pedagogical teaching will not have the desired impact. Therefore, educators need to first understand the 4G model (which is the spine of this academic strategy) and effectively use them to change the pedagogy as well as to promote andragogy or adult learning.

\section{Methodology}

The purpose of this mini-study was to assess the efficacy of our approach to reconstruct the global education and learning strategies to enhance 21st century learning skills in conjunction to learning experience on a global perspective across curriculum. We sought to answer the following questions associated with the 21st century learning skills, based on the research enunciated by Suto and Eccles (2014):

1. What is a $4 \mathrm{G}$ education model, and how might it be encouraged?

2. What are the expectations of Baby Boomers, Generation Xers, Millennials (or Gen Y) and Centennials (or Gen $\mathrm{Z}$, iGen) for the learning environment?

3. What are the unique learning propositions of the different generations in the $4 \mathrm{G}$ educational landscape? 
4. How and why do generational cohorts view technology use, leadership, mentoring, and employee evaluation differently?

5. What methods can be implemented in the learning community to effectively teach multiple generations?

6. How do the different generations view effective teaching, learning, and leading?

These are broad questions. We recognised that it is quasi-scientific study, but with our small population, we would not be able to gather information that would be statistically significant. But with the small population, the researchers were able to get many in-depth discussions going since people talked more in small groups while they encouraged each other in search for better, if not, the best answers. Then again, more importantly, the research aspects of the study for us are the continuous improvement aspects: implement, assess, reflect and adapt. We hope to gain quality, actionable feedback from our survey questionnaires allowing us to make improvements during the 4-months period before fully implementing the project. Nonetheless, the researchers must stress that they approached the study with strict objectivity, researchers' dutiful observation and logical thoroughness to get the finest responses and answers to the questions posed. Being well-organized, the researchers, with the help of the organizational members - chiefly, the Senior Management Team, planned and maintained good timetabling and scheduling of interviews, data collection, discussions, and analysis as stated by Jankowicz (2005).

Members of the senior management team addressing the learning organisation as part of the strategic planning exercise were:

1. SMT 1-5 (5 x Senior Management Team),

2. HOS 1-5 (5 x Head of Schools)

3. SBT 1-2 ( 2 x Two Senior Business Teachers)

The 12 respondents together had over 80 years of leading and teaching experience with rich local and international exposure. Towards the end of the process, each member of the senior management team was interviewed. Each interview lasted approximately 30-45 minutes. These interviews were completed during the final third week of October 2017. The interviews were open-ended, but the structured schedule was used to provide a common denominator without excessively restricting the parameters of the interviews and the information that might arise.

The main methods for conducting the research were observations, discussions, records of meetings, and a structured set of questions for interviews. At the end of the 4-month period, each of the team members was interviewed about the experience. Observations and interviews were the central means of obtaining data and were supplemented by school documents and marketing collaterals. The discussions ranged from informal discussions with staff from various faculties to formal committee meetings. The observations took place over a 4-month period from July to October 2017. Obviously, there are challenges in trying to generalise from such a set of observations.

Through the observations, discussions and then supplementing them with a set of a more systematic, structured interviews with the executives involved, it was hoped to validate the perceptions of what had occurred. An interview schedule of questions was prepared.

\section{Key Findings}

By the end of the 4-month period from July to October 2017, a series of meetings and discussions were held. The results were compiled and analysed. The key findings are as follows;

\section{The4G Education}

Learning styles are "characteristic cognitive, affective, and psychological behaviours that serve as relatively stable indicators of how learners perceive, interact with, and respond to the learning environment" (Keefe 1979). In the light of this, different generation of learners prefer style that suit them, for example, the Baby Boomers are drawn to theories and abstractions, while Generation Xers prefer active learning and others lean toward introspection. The Millennials and Centennials favour visual presentation of information, yet some prefer verbal explanations. The central tenet is that one learning style is neither preferable nor inferior to another, but is simply different, with different characteristic strengths and weaknesses. Therefore, the aim of instruction should be to equip students with the skills associated with every learning style category, since they will need all ofthose skills to function effectively as professionals (Loh and Teo 2016, Loh and Teo 2017,Keefe 1979). 
There were mixed views from the respondents on the definition of $4 \mathrm{G}$ education is and the collective approach taken by each HOS (Head of School) whom may differ slightly from individual school. In the years spent developing the framework, the SMT (senior Management Team) were all deeply involved. The respondents were asked what learners needed to succeed at all levels.

They unanimously responded that a combination of deep knowledge and what has come to be known as "21st century skills" characterises the essential outcomes learners now need for success.

As one SBT (Senior Business Teacher) commented:

"In our Academy, we have already implemented critical thinking, problem solving, communications skills, innovation skills, technology skills and career and life skills which will be needed far into the next century".

Yet another HOS modestly agreed:

"The PEI that understands the relation between students learning these skills and the future welfare of Singapore will be the ones who invest and develop the best ways to do this. It's precisely why the implementation of the 21st century skills is imperative for PEIs".

Encapsulating the one-on-one meetings and discussions with respondents on enhancing student learning: the following salient points were highlighted:

- Collaborative learning where students can also share their thoughts, researches and ideas. They put up papers and do case studies and conduct researches.

- Connected networks where students are connected to the internet of things and to information through technological support to their ideas and concepts.

- Technology playing a crucial part in the delivery and sharing of information.

- Groups working together to argue cases and agreeing on a solution based on facts and findings, and presenting them effectively.

- Learners exposed to industries and workplace environments to effectively underscoring learning concepts at work and creating opportunities for learners and employers to network. It also includes out of class learning experience.

- Real-life projects undertaken by learners that are tested at workplace and industries to see the direct results.

\section{Digital Disruption}

The digital disruption is here to stay. Digital disruption here can be described as a transformation that is caused by emerging digital technologies and business models. These new creative technologies and models can impact the value proposition of company's product offerings and services offered in the market place.

Learners' expectation across different generation differs significantly. For example Gen $\mathrm{Z}$ is a generation of highly-educated, technologically-savvy, innovative thinkers. They search for solutions and set out to make things on their own. With this level of self-direction and purpose, it's not surprising Gen Zers also want learning ondemand (mobility), across different culture and space for experiential learning. They challenge traditional ideas of use, form and function when it comes to all facets of learning and teaching. As opposed to Baby Boomers, Generation Xers, Millennials (or Gen Y), the Gen Zis open-minded and adaptable, not a group known for fixed opinions or inflexibility (which apply to Baby Boomers).

Hence, to maintain a high level of learning and engagement of leaners, it requires the following characteristics and expectations from different generational learners:

\begin{tabular}{|l|l|l|l|l|l|}
\hline SN & Description & $\begin{array}{l}\text { Baby } \\
\text { Boomers }\end{array}$ & $\begin{array}{l}\text { Generation } \\
\text { Xers }\end{array}$ & Millennials (or Gen Y) & $\begin{array}{l}\text { Centennials (or } \\
\text { Gen Z, iGen) }\end{array}$ \\
\hline 1 & $\begin{array}{l}\text { Maintain an atmosphere of academic } \\
\text { integrity, respect and civility. }\end{array}$ & $\sqrt{ }$ & $\sqrt{ }$ & $\sqrt{ }$ & \\
\hline 2 & Have a strong work ethic & $\sqrt{ }$ & $\sqrt{ }$ & $\sqrt{ }$ & \\
\hline 3 & Manage their time wisely & $\sqrt{ }$ & $\sqrt{ }$ & $\sqrt{ }$ & $\sqrt{ }$ \\
\hline 4 & Participate actively in class & & & $\sqrt{ }$ & $\sqrt{ }$ \\
\hline 5 & Properly approach out-of-class learning & & & $\sqrt{ }$ & $\sqrt{ }$ \\
\hline 6 & Reflect on the educational process & & & $\sqrt{ }$ & $\sqrt{ }$ \\
\hline 7 & Perform self-assessment & & $\sqrt{ }$ & $\sqrt{ }$ & \\
\hline
\end{tabular}




\section{Adapted from Penn State: Expectations for a Vibrant Learning Environment}

According to one of the senior business teachers in terms of the impact of teaching and learning vis the students, they are better engaged and learn more deeply when they are taught in the context and environment where that learning normally occurs, such as solving a real-world problem. Therefore, PEIs that take advantage and adapt quickly will have better success. To overcome these challenges and to ensure successful accomplishment, the programmes (or courses) offered by the Academy must be:

- Flexible

- Personalised

- Experiential

- Data led learning

- Community and Socially connected learning

- Assessments must also move away from paper and pencil to computer based

\section{The Student Journey}

Teachers are at the heart of this whole journey. Teachers take it upon themselves to guide students, creating the time and space for students to have experiential learning. Teachers know that exams and results are not the end of education. But more importantly, for students to develop into a confident, empathetic and resilient individual and they grow all the attributes that make a complete person. Students need to know the basics of applications and research (4Es: Enquiring, Exploration, Experimentation and Extension to uses within the Industry) as well as upgrading of skills to go excellence and beyond.

Therefore, to meet demands of new global education, the Academy has put in place the learning environment vis infrastructure, and technology. The Academy made clear their commitment to global education and consequently boosted the confidence of both students and teachers alike.

Extant literature highlights that how and where students learn affects their retention. To this end, cultivating 21st Century Skills, it is imperative that education take shape within flexible, adaptive contexts that inspire a sense of community and promote formal and informal learning. The learning modality should also facilitate impartial access to quality learning tools, technologies, and resources (Sak-Min 2007; Black 2007). It lends credence to the Partnership for 21st Century Skills framework which provides an all-inclusive strategy allowing learners to possess global competencies and international understanding, thus enabling them to have a global perspective in the 21 st century.

There are several different experiences in the student learning journey; teaching is just one of them. Learning can also be acquired independently through study or play. Conversely it can be assimilated through interaction and informal sharing with others and vice-versa. We can also learn by doing, through trial and error.

One of the senior business teacher stressed that the integral part of learning today is learning through internships and workplace learning.

"In the learning journey, students should be offered a wide variety of ways to learn, among which they could choose or with which they could experiment. They do not have to learn different things the same way. They should learn at a very early stage of education process that learning how to learn is largely their responsibility - with the help they seek but that is not imposed on them"

Consistent with Darling-Hammond's (2006) view of best practices in teaching and learning, 21st Century Skills set in when teachers:

1.Begin with real-world problems and processes

2.Support inquiry-based learning experiences

3.Provide opportunities for collaborative project work

4.Emphasize how to learn (i.e., above what to learn)

Haensly, Lupkowski and Edlind (1985) rightly pointed out that many students appear to gain traction with activities outside of the classroom location. These activities are also known as the extra-curriculum activities (ECA) usually connected or peripheral to their academic courses. Through the ECA, students also develop other related skills e.g. psychomotor talents; leadership skills, and future career and occupational skills. 
Interpersonal and social strategies - proficiencies not considered basic elements of the academic curriculum may especially be constructed through participation in the extracurriculum. In the same vein, the Academy will go a little further in providing the best education by ensuring the learners are sitting in the subscribed programme because of their interest and aspirations; and not simply choosing a programme of study. To allow this to happen, the Academy will implement the "learning journey".

The diagram below illustrates the learning journey of the ABC Academy students:

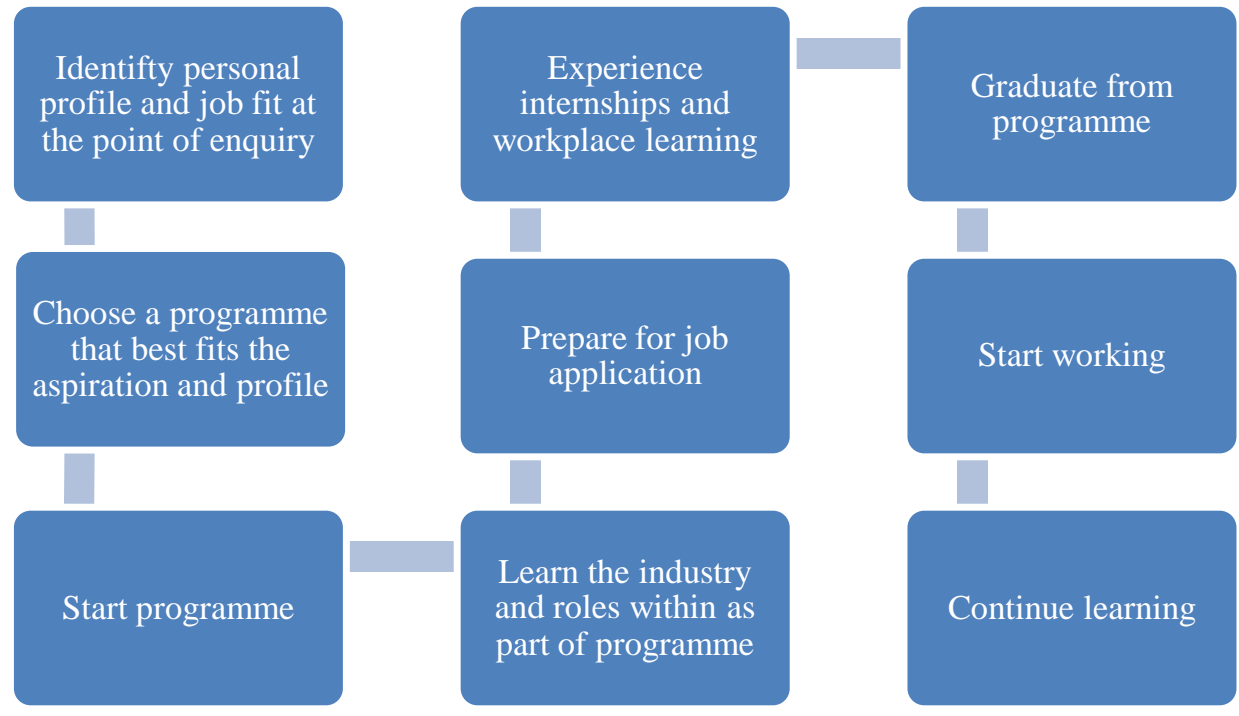

\section{The Arduous Role of Teachers in the ABC Academy}

Students at the Academy would find it challenging to obtain 21st Century Skills without the guidance of welltrained teachers who have direct instructional knowledge in this area. Indeed research show that many teachers are unacquainted with 21st Century Skills and instructional technologies (Boholano 2017, Kennedy et al 2016, Young 2014, Maxwell 2009, Cuban 2003). According to P21, quality professional development ensures educators understand the importance of 21st Century Skills and how to integrate them into daily instruction through a variety of tools (Partnership for 21st Century Skills 2006).

Hence, the role of teachers at the Academy becomes multi-faceted; they are not only teaching for technical competencies, but also mentors to prepare students for the workplace, and a friend or a buddy as well as a role model and with high value of integrity (Low and Ang, 2011) to develop them holistically to perform well to create an impact. Therefore, the Academy teachers are to be:

- Technically competent (Maxwell, 1993), being experts at their subjects

- Industry-experienced, being practical and pragmatic so they can bring practical knowledge and knowhow to the learning area.

- Good managers, planning (Maxwell, 1993) time and space to deliver the best results given their multi-facetted responsibilities as well as being proactive (Covey, 1989; Low, 2017; Eat your career.com, 2017).

- Action-based - working out the example(s) (Low, 2017), example-setters and role models (Low, 2018)

- Good listeners, communicating and listening with high emotional quotient with empathy and character

- Critical thinkers, identifying the logic behind the change and transformation and making things happen most effectively and productively as well as seeing things through to meet the intended outcome(s).

- Great collaborators and team players, working as collaborators and team-players (as a team) to deliver results (Low, 2018; 2003; Maxwell, 1993).

- Technologically savvy - to make technology work effectively to deliver intended results

As Low (2017) observed, the entire organization i.e., the Academy overall then, benefits from having proactive leaders, managers and people. To paraphrase, they, the teachers and students become the Academy's pluses as well as bundles of energies, moving the Academy forward.Walt Disney once said, "The way to get started is to quit talking and begin doing." (https://www.pinterest.com/explore/proactive-quotes/, also cited in Low, 2017). In being proactive, until and unless one acts, then something is done; there's change. 
Note that pro-activeness, taking the lead, is really powerful and helpful in terms of affecting one's personal change as well as influencing others and changing the world around oneself.

\section{Applied Learning}

According to Singapore's MOE (Ministry of Education) (2018), Applied Learning refers to an approach that emphasises authentic and practice-oriented learning experiences, and is not necessarily restricted to vocational or technical education. It gives students additional opportunities to acquire skills and qualities based on the practical application of knowledge in real-world contexts, and strongly support our focus on developing 21st century competencies and values in our students.

Applied Learning in schools is characterized by these features:

a. Emphasises the relevance of what is being learnt to current needs and future trends of industries;

b. Provides hands-on or experiential learning for students to enact authentic scenarios;

c. Equips students with the skills to engage in the practical application of knowledge; and

d. Could involve partnering the industry, community, institutions of higher learning, and/or professional training bodies.

It is small wonder that the Academy has made it mandatory for learning to be inclusive and more importantly in global education, student's learning must be applied. As an example, one respondent in the Senior Management Team cited that:

"Applied Learning enable students appreciate the relevance and value of what they are learning in the academic curriculum to the real world, in turn gives them stronger motivation and determination to deepen skills and knowledge. The focus is on the application of thinking skills, integrating knowledge across subject disciplines, (in extending their imagination) and relating these in real-world settings in society and industries".

As one Senior Business Teacher retorted when asked what is Applied Learning means to students:

"It is an approach of learning for students. It is not for less academically endowed students. Students who participated in the work placement or internship - learn by applying and by doing, and they learn beyond the classroom. They understand and can translate what they have learnt to the real world. My personal observation with students tells me that they (students) truly enjoy learning and are self-motivated. These are powerful learning experiences and they stick for life!"

If educators deliver applied learning correctly, and student sees value in how education institutions can successfully deliver applied learning, then PEIs will react and restructure their curriculum. They will think that the imperative now is how to reach out to the industry to find good internships, to find good placements, and to reconsider the time students spend within the campus, so as to ensure that it is intrinsically relevant.

In delivering Applied Learning, there are obviously barriers, one of each is the cost imperative for business and the other is the capacity of SMEs (Small Medium-size Enterprises) as well as MNCs (Multi-National Corporations) to accept interns. There are limitations as to how many interns SMEs and MNCs can absorb based on their schedule and agenda. But the advantages outweighs the disadvantages, by exposing industry partners to PEIs' thrust of Applied Learning, one of the skills transferred is the ability of the industry to provide training in a better, more coherent and more effective manner. This builds confidence for them to play a part in the education of the next generation. Conversely, allowing them to constructively play a role in the development of skills for their industry.

\section{The TNE Equation}

The relentless drive toward learner's 21 st Century Skills by PEIs is well reinforced by research, moreover harnessing the role of Information and Communication Technology (ICT) suggest that synchronous and asynchronous learning via new media stimulates student learning (McFarlane 2003; Andretta 2005). For over a decade, PEIs in Singapore have been quick to adopt the 21 stcentury readiness of all learners, the central question is how and to what extent implementing technology and the pertinent approaches by individual PEI will determine its advantage over competing PEIs. Along with the fundamental changes in the economy, (owing to the technology advancement and digital disruption), have somewhat recalibrated the job market vis the basic skills that drive manufacturing industry are now swapped by non-routine, creative, and collaborative problem-solving tasks. In response to the growing demand from the education community, the academy is addressing technological 
support for transnational education (TNE), providing cost-effective, appropriate and reliable solutions and services overseas. The transnational education is an area of importance and development in Singapore education sector. It refers to the provision of education programmes from institutions in one country to students in another.

With the ABC Academy expanding into other territories under the hub and spoke Transnational Education (TNE) model, it becomes more critical that the education programmes between the destinations are aligned as well. To meet some of the learning outcomes and to create a collaborative value chain, there must be more interaction between the destination campuses. Programmes schedules and project must now be aligned; student projects can now be cross-destination with students interacting with one another through skype and conference calls to meet to discuss projects for a collaborative project presentation, led by teachers on both sides. Interaction between teachers in different destinations becomes a key component for success in classrooms and student experience.

\section{Caveats and Other Issues}

The key imperative of education remains, at least in Singapore, to meet national needs - to earn our own living, create good jobs for our people, and help them excel at work and in life. Education also instils common values and languages, along with shaping the worldview of our young. But at the same time, individuals naturally wish to make their own choices in education based on their aspirations and needs, especially when technology is opening up so many tremendous career opportunities. Education systems must therefore also help people uncover and pursue their passions, and chase their respective rainbows.

It is critical that learners know and be aware that there is a big and great difference between data gathering and data analysis, and examples and real issues be made clear to these learners. They may be technical savvy in gathering data but they have to learn to organize and analyse well too.

Interpersonal/ networking and cooperation/ collaborative skills must be drilled into the students; and such skills would anchor them to job success.

Being entrepreneurial is critical to one's job success (Gabriel, 1999).Students must indeed learn a marketable skill. And get creative, move into action and do business (Tobak, 2018). [Tobak (2018) highlighted among other cases

i) The Howard Schultz way: The Milan trip gave a young marketer working for a Seattle coffee bean roaster an idea for upscale espresso cafes like they have all over Italy. His employer had no interest in owning coffee shops but agreed to finance Schultz's endeavor. They even sold him their brand name, Starbucks.

ii) The Konosuke Matsushita way: In Japan in 1917, a 23-year-old apprentice at the Osaka Electric Light Company with no formal education came up with an improved light socket. His boss wasn't interested so young Matsushita started making samples in his basement. He later expanded with battery-powered bicycle lamps and other electronic products. Matsushita Electric, as it was known until 2008 when the company officially changed its name to Panasonic, is now worth $\$ 66$ billion.]

Internships and work experience are important and such experiences contribute to the ingredients of job success after university education. After all, as Paulo Coelho once said, "Be brave. Take risks. Nothing can substitute experience" (BrainyQuote, 2018) or to the authors, nothing can substitute action with experience or "assamgaram" (a Malay word, literally meaning, sour and salty) that is, to have much practical experience and/ or to know the ins and outs of certain subject matter. Social media and other communication tools are to be tapped to encourage learning both in the universities and at the workplace. To refute the issue as to whether student's academic learning vis mathematics and language proficiency outweighs the importance of learning soft skills:

According to one respondent, a senior management team reiterated that the best learning happens when students learn core subjects and processes, such as the rules and procedures of mathematics, at the same time that they learn how to think and solve problems.

"We now know that motivation and engagement are crucial to learning success. More than the knowledge that teachers impart, it is perhaps even more important to have the values that you are teaching. It is really the ultimate holistic bringing together of a complete education, where we develop our learners in intellect, empathy and values. Further by integrating the learning of core knowledge, key 21st skills, the effective use of technology and applying this learning to relevant, real world problems and questions, in every classroom, we will be preparing our young for the future of our nation".

In particular, both Millennial and Centennial learners have always wanted to be more engaged in their learning, with pertinent materials and content that relate to their lives and the issues of the times. 
That pressure is higher now than ever before, as "digital native" students, immersed in today's technologies, have access to more information and thinking tools than ever before. Nonetheless both educators as well parents now have a special accountability in guiding students toward the effective use of these technology for improved learning that meets the needs of our times.

\section{Benefits and Limitations}

The authors recognise that they do not have a large enough number of participants but limited to select topechelon educators in a PEI based in Singapore, nor enough number of participants in the voluntary survey for the results to gather statistically significant or general sable information. In addition, the survey instrument needs to be refined to enable wider scope of questionnaires and responses in future data collection.

\section{Conclusion and further recommendations}

In higher education, academic learning is paving way to a more experiential form of learning. It has become normal for students to do internships, perform community service, and embark on overseas exchange or immersion programmes. Digital literacy is progressively becoming compulsory across the board for all students. In the PEIs, we are transforming into centres for lifelong learning, so that they can keep up with the rapid advancement in knowledge and skills. The Academy has decided that enrolment should be for 20 years and not three years - a very bold but important move. The students graduate after three years, but they can come back to learn the latest technology or skills in their field. These ensure linkages, information exchanges, close associations and/or continuous as well as applied learning among the key players, the Academy, the companies (industries) involved and the student graduates with feedback and adjustments during the years to come.

In line with the public institutions, the PEIs in Singapore must step up their role in delivering continuing education and training, transforming themselves with technology to enhance the learning and training needs of adult learners. For example, PEIs must move quickly beyond traditional classrooms on campus to becoming centres of lifelong learning for all. Through technology, PEIs can facilitate learning at our fingertips for example mobiles, smart devices delivering knowledge online, anytime, and anywhere.

The advent of MLCs (Micro-learning courses) in today's educational landscape allow for short courses consisting of lessons which take only 15 minutes or less to complete. With bite-sized MLCs, it is possible to learn in our spare time or while commuting locally or overseas and finish the MLC in 10 to 20 lessons. With this modality, we can see how our learning comes to fruition. Furthermore, a useful feature of the MLCs is the online learning community formed around each course that offers a platform for learners to share their experiences and problemsolving tips. These online communities not only enrich the participants' learning journey, they also make the lessons and courses come alive.

The pace of MLCs implementation will signal PEI's commitment to continually provide the workforce with new avenues, opportunities, and platforms to upskill and reskill besides delivering (offering) courses from traditional classrooms. Invariably, modern learners will increasingly choose this as a viable and suitable alternative to traditional learning. It will energise our workforce and raise its productivity, as well as enhance our people's skills and passion for learning.

With the students' needs/excellence and the future (the students' and the Academy's) in mind, we need to scrutinise carefully the various pathways that are appropriate for different groups of students, and enable them to achieve good outcomes vis grasping of 21st Century Skills. For example, there are debates today that have even called into question the value of a university degree, as the proliferation of university graduates necessitates employers to identify other forms of differentiation when selecting talent.

Looking ahead, as it takes time to co-ordinate and effectively impact standards, assessments, curriculum, instruction, practical sessions/ internships, professional development, and learning environments, we recommend the prudent approach to learning and curriculum development vis focused on what are the important themes and big ideas in each subject area, and how 21st century skills can be integrated with this more focused set of learning goals.

In summary, life as in education, is filled with both constants and as well as variables, the researchers have just provided a simplistic view of one PEI's (in Singapore) current situation. We must appreciate the depth of the constants, and embrace the uncertainties and excitement of the variables. 


\section{References}

Ackoff, Russell L., and Greenberg, Daniel (2008).Turning Learning Right Side Up: Putting Education Back on Track, Prentice hall, Upper Saddle River, New Jersey 07458.

Andretta, S. 2005. Information literacy: A practitioner's guide. Oxford, UK: Chandos Publishing, Ltd.

Black, R. 2007. Fanfiction writing and the construction of space. E-Learning and Digital Media,Vol. 4 No. 4

Boholano, Helen B. (2017). Smart Social Networking: 21st Century Teaching and Learning Skills, Research In Pedagogy, Vol.7, Issue 1.

BrainyQuote (2018) 'Paulo Coelho Quotes', Website: https://www.brainyquote.com/authors/paulo_coelho Accessed on 30 April 2018.

Cheng, K.M. (2003). Sujing.Hong Kong Economic Journal, 13 December 2003Covey, S.R (1989).The seven habits of highly effective people, Simon and Schuster: USA.

Crowther, F., Hann,L. \& McMaster, J. (2000) Leadership for Successful School Innovation: Lessons from the Innovation and Best Practice Project (IBPP). A Report from the Innovation and Best Practice Project (IBPP) to DETYA

Crowther, F., Kaagan, S., Ferguson, M. \&Hann, L. (2002) Developing Teacher Leaders: How Teacher Leadership Enhances School Success. Thousand Oaks, CA: Corwin Press

Cuban, L (2011). Teacher Resistance and Reform Failure.https://larrycuban.wordpress.com/2011/04/30/teacherresistance-and-reform-failure/ Accessed on 18 April 2018.

Darling-Hammond, L. (2006).Powerful learning —What we know about teaching for learning. New York: Jossey-Bass.

Eat your career.com (2017). 'How to be proactive at work: My 5 step system', Eat your career.com. Website: http://www.eatyourcareer.com/2010/08/how-be-proactive-at-work-step-system/ Accessed on 10 Mar 2017; 11 Oct 2017.

Felder., R. N., \& Brent, R., (2007), Cooperative learning, Raleigh, NC 27695-7905 2, Education Designs, Inc., Cary, NC 27518, N.C. State University

Gabriel, V. A. (1999) Success in the food business, Ranks Books: Singapore.https://www.pinterest.c om/explore/proactive-quotes/ Accessed on 16 Jan 2018.

Greenberg, J., \& Barron, R. A. (2000).Behavior in organizations (7th ed.), Upper Saddle River, NJ: Prentice Hall.

Greenhill, Valerie (2010). 21st Century Knowledge and Skills in Educator Preparation, This paper has been produced as part of a collaborative project by the American Association of Colleges of Teacher Education and the Partnership for 21st Century Skills (P21).

Haensly, P. A., Lupkowski A. E. \&Edlind E.P. (1985) The Role of Extracurricular Activities in Education, The High School Journal, Vol. 69 No 2, pp110-119.

Jankowicz, A. D. (2005). Business Research Projects, Thomson Learning: London.

Keefe, J.W. (1979). "Learning Style: An Overview," in Keefe, J.W., ed., Student Learning Styles: Diagnosing and Prescribing Programs, Reston, Va.: National Association of Secondary School Principals.

Kennedy I.G., Latham G., Jacinto H. (2016) The Literature Review. In: Education Skills for 21st Century Teachers. SpringerBriefs in Education. Springer, Cham

Lea, S.J, Stephenson, D., \& Troy, J. (2003).Higher education students' attitudes to student-centred learning. Beyond educational bulimia'? Studies in Higher Education, 8(3), 321-334.

Ledward, B. C., and D. Hirata (2011).An overview of 21st century skills.Summary of 21st Century Skills for Students and Teachers, by Pacific Policy Research Center. Honolulu: Kamehameha Schools-Research \& Evaluation.

Loh, C.Y. and Teo, T.C. (2016).Students' Perception of Collaborative Learning, Conflict Management and Satisfaction in a Private Educational Institution Learning Environment: An Asian Case Study, Journal of Education \& Social Policy. Vol. 3, No. 3.

Loh, C.Y. and Teo, T.C. (2017).Understanding Asian Students Learning Styles, Cultural Influence and Learning Strategies, Journal of Education \& Social Policy Vol. 7, No. 1; March.

Low, K.C.P. (2018) (2 ${ }^{\text {nd }}$. Ed.) Leading successfully in Asia, Springer: Heidelberg, Germany/ London: UK/ New York: USA.

Low, K.C.P. (2017). 'Being Proactive, the Steps: the 7 Ps Involved and the Importance and Benefits of Being Proactive', Kazakh Leading Academy of Architecture and Civil Engineering: KazGAS's "New Construction Trends in the $21^{\text {st }}$. Century devoted to the $80^{\text {th }}$ Anniversary of KulibayevAskarAltynbekovich" (Section 'Architectural and Construction Education' of the IEC of KazGASA) Conference on 29 June 2017 at Almaty, Kazakhstan

Low, K.C.P. (2003) Team Success, BusinesscrAFT Consultancy \& Humber Lincoln Resources: Singapore. 
Low, K.C.P. and Ang, S.L. (2012). 'The theory and practice of Confucian value of integrity: The Brunei Case Study', International Journal of Business and Management; Vol. 7, No. 14; 2012, p. 114-124.

Maxwell, D. (2009). Engaging the next generation of faculty. Presidency, Vol.12 No.1, pp 5-7.

Maxwell, J. C. (1993). Developing the leader within you, Thomas Nelson, Inc.: USA.

McFarlane, A. (2003). Assessment for the digital age.Assessment in Education: Principles, Policy \& Practice, Vol.10, pp 261-66.

MOE (2016).Ministry of Education website https://www.moe.gov.sg/Accessed on 18 April 2018.

MOE (2018).Ministry of Education website, https://www.moe.gov.sg/education/secondary/applied-learning Accessed on 5 May 2018.

P21 (2014), Framework for State Action on Global Education, Partnership for 21st century learning, 1 Massachusetts Avenue NW, Suite 700, Washington, DC 20001.

Sack-Min, J. (2007).Building the perfect school, American School Board Journal, October 2007.

Schmoker, M. (1999).Results: The key to continuous school improvement, Alexandria, VA:Association for Supervision and Curriculum Development.

Shimazoe J., and Aldrich, H., (2010), Group Work Can Be Gratifying: Understanding \&Overcoming Resistance to Cooperative Learning, College Teaching, Vol. 58, 52-57

Smylie, M. \& Hart, A. (1999) School leadership for teacher learning and change - A human and social capital development perspectives. In Handbook on Research on Educational Administration, pp. 421-41. San Francisco, CA: Jossey-Bass

Stover, Dell (2018), Building the Perfect School, American School Board Journal, February 2018.

Sturgess, G. (2006). Blair's public service revolution - and how it's influenced Australia. The Public Sector Informant, October, pp. 8 \& 21

Suto, Irenka and Eccles, Helen (2014), The Cambridge approach to 21st Century skills:definitions, development and dilemmas for assessment, IAEA Conference, Singapore

Teo, T.C. and Low, K.C.P. (2018).Strategic Thinking \& Insights, Partridge: Singapore.

Tobak, S. (2018). ' 8 Great Entrepreneurial Success Stories', entrepreneur.com.

Website:https://www.entrepreneur.com/article/243099 Accessed on 30 Apr 2018.

Young, David (2014). Global education for every student; 11/23/2014 Global Education

http://www.seenmagazine.us/Articles/Article-Detail/ArticleId/4387/GLOBAL-EDUCATION-FOR-EVERY-

STUDENT Accessed on 18 April 2018. 